\title{
Radiofrequency Coblation versus Surface Bipolar Cautarization for the Treatment of Inferior Turbinate Hypertrophy
} Abdel-Zaher El-Sayed Tantawy, Ahmed Soliman Ramadan, Sara Mielod Youssef Moamar*, Ashraf El-Hussieny Oda Basha

Department of Otorhinolaryngology, Faculty of Medicine Zagazig University, Egypt.

*Corresponding Author: Sara Mielod Youssef Moamar, Mobile: +218925624278, Email: boost.balm83@yahoo.com

\begin{abstract}
Background: Nasal obstruction is the foremost complaint of a large number of patients in otolaryngologic practice most commonly caused by inferior turbinate hypertrophy. Objective: This study aimed to compare surface bipolar electrocautery with radiofrequency coblation in the treatment of inferior turbinate hypertrophy.

Patients and Methods: This clinical trial study was conducted at ENT Department, Faculty of Medicine, Zagazig University Hospitals in the period from May 2020 to Jul 2021, included 34 patients with nasal obstruction due to hypertrophied inferior turbinates (HIT) resistant to medical treatment for a period not less than six weeks. The first group included 17 patients with HIT treated by bipolar cauterization and second group include 17 patients with HIT treated by radiofrequency coblation. Results: This study showed that nasal obstruction showed significant improvement in both groups postoperatively. There was no significant deference between both regarding nasal obstruction although there was improvement in objective evaluation. In addition, there was no crustation observed in nasal mucosa among patient. The discharge and crustation were significantly associated with bipolar group.

Conclusions: Both techniques have proven to be equally effective. In both the groups, radiofrequency is considered to be more accurate. Bipolar electrocautery and radiofrequency volumetric tissue reduction are equally effective in improving both the subjective and objective nasal obstruction.
\end{abstract}

Keywords: Bipolar electrocautery, Nasal obstruction, Radiofrequency, Turbinate hypertrophy.

\section{INTRODUCTION}

One of the major causes of nasal obstruction is inferior turbinate hypertrophy (ITH). ITH is commonly associated with chronic allergic or vasomotor rhinitis ${ }^{(\mathbf{1})}$. These conditions are traditionally treated conservatively with topical corticosteroids, antihistamines, decongestants, and immunotherapy. However, medical therapy is frequently ineffective in relieving nasal obstruction and has the added risk of progressive consumption leading to iatrogenic effects such as rhinitis medicamentosa ${ }^{(2)}$. For these reasons, surgical intervention is commonly employed in the treatment of chronic nasal obstruction secondary to ITH. A myriad of surgical options exists to include partial or total turbinectomy, laser-assisted turbinoplasty, submucosal resection, electrocautery, cryotherapy, corticosteroid injection, turbinate outfracture, radiofrequency volumetric tissue reduction, and most recently, radiofrequency coblation $^{(3)}$. The severity of complications, vary with increasing degrees of invasiveness and range from minor bleeding to significant hemorrhage, synechia, crusting, foul odor, pain, hyposmia, and chronic dryness. There have been many studies comparing the various surgical techniques ${ }^{(4)}$.

Many procedures have been described for the surgical management of inferior turbinate hypertrophy. Coblation is a relatively new technology that used radiofrequency energy to ablate hypertrophied tissues. The standard method of using this technology has been shown to be effective ${ }^{(5)}$. The proposed benefit of the radiofrequency (RF) technique is the maintenance of the surface mucosa, thereby maintaining the physiologic role of the turbinates in creating turbulent airflow, airway resistance, warming and humidifying inspired air. As a result, there has been a trend toward the intramural or submucosal surgical modalities ${ }^{(2)}$.

Surface bipolar cautery has been the method of choice for many surgeons. This is due to the low cost, ease of use, and ability to perform under local anesthesia. The relatively novel technique of RF coblation offers similar benefits but may have the added benefit of improved mucosal preservation and tolerance by the patient ${ }^{(6)}$. This study aimed to compare surface bipolar electrocautery with radiofrequency coblation in the treatment of inferior turbinate hypertrophy as regards to objective and subjective improvement in nasal obstruction, rate and type of complications, experience during the procedure, and rate of recovery.

\section{PATIENTS AND METHODS}

This study included 34 patients (divided into 2 groups; 17 patients each) with nasal obstruction due to hypertrophied inferior turbinates resistant to medical treatment for a period not less than six weeks. Our study included 10 males and 24 females with mean age of 28.7 years (range 18-50 years). The study work was done in Otorhinolaryngology Department in Zagazig University Hospitals in the period from May 2020 to Jul 2021.

\section{Ethical approval:}

Written informed consent was obtained from all participants. The study was approved by the Research Ethical Committee of Faculty of Medicine, 
Zagazig University (ZU-IRB\#4156). The work has been carried out in accordance with The Code of Ethics of the World Medical Association (declaration of Helsinki) for studies involving humans.

We considered the following Inclusion criteria: Age; 18-50 years old. Gender; male and female. Persistent nasal obstruction due to hypertrophy of the inferior turbinates. Fit for general anesthesia. Our exclusion criteria were: Significant nasal septal deviation. Nasal polyposis. Acute Rhinitis. Chronic sinusitis. Patients with tumor of the nasal cavity. Patients with maxillofacial trauma. Patient who doesn't have subjective improvement following the application of topical $0.05 \%$ oxymetazoline. Patients with severe medical comorbidities or contraindications to surgery.

\section{Steps of performance before surgery:}

All studied subjects were subjected to: Full history taking. Complete physical examination for all patients. Anterior rhinoscopy. Nasal decongestion to allow better examination of the nose and to see the response of mucosa to decongestion. Nasal visual analogue score to assess the severity of nasal obstruction. Nasal endoscopic examination.

The endoscopic evaluation was carried out with a straight $\left(4 \mathrm{~mm}, 0^{\circ}\right)$ endoscope before the nasal mucosa was decongested. Routine laboratory investigations included complete blood picture, liver function tests, kidney function tests, random blood sugar, coagulation profile, viral markers ....etc. CT scanning of the nose and paranasal sinuses was done for each patient.

\section{Medical treatment:}

Medical treatment was given to all patients before CT scan in the form of; Nasal decongestant drops twice daily for three days. Antihistamines. Antibiotics, if there is suspected infection (amoxicillin clavulanic, e.g. Augmentin 1 gm twice daily for 7 days). Local steroid spray.

If patients did not improve after six weeks from medical treatment, we would use surgical treatment.

\section{Surgical treatment:}

Noradrenaline 1:200.000-soaked cotton pledgets was applied to bilateral nasal cavities for approximately 5 minutes. Each patient then underwent turbinate reduction using either bipolar electrocautery or RF coblation. All surgeries were performed under general anesthesia with endotracheal tube. The patients were positioned in a standard nasal surgery position. All surgeries were done using 0-degree (straight) endoscope.

\section{Surface bipolar cauterization ( $1^{\text {st }}$ group) :}

Endoscopic evaluation of the inferior nasal turbinate was done then the Valleylab bipolar cautery tip was connected to the Valleylab Force 2 electrosurgical system. The procedure involved 2 passes (medial and inferior) surface of inferior turbinate sparing the anterior end. The bipolar was set to a power setting between $(15 / 20 \mathrm{j} / \mathrm{s})$ and each probe was activated and held in place for exactly 2- 4 seconds (100 J applied with each pass) or stopped in less than 4 seconds if mucosal blanching is noted. Linear cautery of inferior turbinate was done from posterior to anterior with $2 \mathrm{~mm}$ distance between two limbs of bipolar cautery forceps. A silastic nasal septal stent was fixed to the septum and left for at least 2 weeks. Pack was inserted at this side to avoid bleeding.

\section{Radiofrequency coblation ( $2^{\text {nd }}$ group):}

Radiofrequency coblation was performed using the Coblator II System with the Reflex 45 wand (Arthrocare, Sunnyvale, California, USA). The system was set to a power level of 4 in coblation mode (output voltage of 237.5 root-mean-square voltage $(\mathrm{Vrms}) \pm 10 \%)$ and a power level of 2 in coagulation mode (output voltage of $70 \mathrm{Vrms} \pm 10 \%$ ). The coblation wand has 3 markings, which are utilized to gage the depth of penetration of the wand. The wand was inserted starting from anterior head of inferior turbenate up to the $1^{\text {st }}, 2^{\text {nd }}$ and or $3^{\text {rd }}$ marking according to the size of the inferior turbinate. Once the $2^{\text {nd }}$ or $3^{\text {rd }}$ mark was reached then the coblation was performed for a period of 10 seconds. The wand was withdrawal to the second mark and coblation was done in 10 seconds period and finally it was withdrawal at $1^{\text {st }}$ mark and coblation was repeated to another 10 seconds. So duration ranged between 60-90 seconds according to number of passages. We made 2 to 3 passages (superior, middle and inferior). Pack was inserted at this side to avoid bleeding.

\section{Postoperative medication:}

Antibiotics, analgesics, systemic decongestant. Avoid manipulation of the nose and nasal blowing.

Removal of nasal packs was done after 48 hours. Then nasal saline irrigation was prescribed for 2 months postoperatively. Silastic nasal septal stent were removed after 2 weeks.

\section{Postoperative follow up:}

Patients were followed up weekly, $1^{\text {st }}$ month then monthly for one year. On follow up careful recording of symptoms (nasal obstruction, headache and rhinorrhea) was done by visual analogue scale (VAS). In every office visit patients underwent nasal endoscopy and saccharine test. All results and findings were collected and tabulated.

\section{Statistic analysis}

Data were collected, tabulated and statistically analyzed (IBM SPSS Statistics for Windows, Version 23.0. Armonk, NY: IBM Corp.). Quantitative data were expressed as the mean \pm SD and median (range), and qualitative data were expressed as frequency and percentage. Mann Whitney U test was used to compare between two groups of non-normally distributed variables. Percent of categorical variables were compared using Chi-square test or Fisher Exact test when appropriate. Paired categorical variables were compared using McNemar test. Paired ordinal variables were compared using marginal homogeneity test. All tests were two sided. P-value $<0.05$ was considered statistically significant and p-value $<0.001$ was considered statistically highly significant. 
RESULTS

Table 1 shows the demographic characteristics of studied patients.

Table (1): Demographic characteristics of studied patients $(\mathrm{N}=34)$

\begin{tabular}{|c|c|c|}
\hline & $\mathbf{N}$ & $\%$ \\
\hline $\begin{array}{l}\text { Age per years } \\
\text { Mean } \pm \text { SD } \\
\text { Range }\end{array}$ & \multicolumn{2}{|c|}{$\begin{array}{c}28.7 \pm 8.7 \\
18-50 \\
\end{array}$} \\
\hline \multicolumn{3}{|l|}{ Gender } \\
\hline Females & 24 & 70.6 \\
\hline Males & 10 & 29.4 \\
\hline \multicolumn{3}{|l|}{ Smoking } \\
\hline Non-smokers & 16 & 47.1 \\
\hline Passive smokers & 10 & 29.4 \\
\hline Smokers & 8 & 23.5 \\
\hline \multicolumn{3}{|l|}{ Clinical characteristics } \\
\hline $\begin{array}{l}\text { Resistant allergic rhinitis } \\
\text { to treatment } \\
\text { Yes }\end{array}$ & 34 & 100.0 \\
\hline $\begin{array}{l}\text { Grade of inferior } \\
\text { turbinate hypertrophy } \\
\text { Grade III } \\
\text { Grade IV }\end{array}$ & $\begin{array}{l}18 \\
16\end{array}$ & $\begin{array}{l}52.9 \\
47.1\end{array}$ \\
\hline $\begin{array}{l}\text { Respond to topical } \\
\text { decongested } \\
\text { Yes }\end{array}$ & 34 & 100.0 \\
\hline
\end{tabular}

Table 2 shows a highly significant difference between pre and post treatment as regard headache, nasal itching relief, running nose, blocked breathing, and dry mouth.

Table (2): Comparison symptoms pre and postsurgical treatment of inferior turbinate hypertrophy among studied patients (N. 34)

\begin{tabular}{|c|c|c|c|c|c|}
\hline \multirow{3}{*}{ Symptoms } & \multicolumn{4}{|c|}{ Time } & \multirow{3}{*}{$\mathbf{P}$} \\
\hline & \multicolumn{2}{|c|}{$\begin{array}{c}\text { Pre } \\
\text { Treatment }\end{array}$} & \multicolumn{2}{|c|}{$\begin{array}{c}\text { Post } \\
\text { Treatment }\end{array}$} & \\
\hline & $\mathbf{N}$ & $\%$ & $\mathbf{N}$ & $\%$ & \\
\hline \multicolumn{6}{|l|}{ Headache } \\
\hline Yes & 26 & 76.5 & 14 & 41.2 & 0.0001 \\
\hline No & 8 & 23.5 & 20 & 58.8 & \\
\hline \multicolumn{6}{|l|}{ Sneezing } \\
\hline Yes & 6 & 17.6 & 2 & 5.9 & 0.125 \\
\hline No & 28 & 82.4 & 32 & 94.1 & \\
\hline \multicolumn{6}{|l|}{ Nasal itching } \\
\hline Yes & 14 & 41.2 & 8 & 23.5 & 0.031 \\
\hline No & 20 & 58.8 & 26 & 76.5 & \\
\hline \multicolumn{6}{|l|}{ Running nose } \\
\hline Yes & 34 & 100.0 & 0 & 0.0 & 0.0001 \\
\hline No & 0 & 0.0 & 34 & 100.0 & \\
\hline \multicolumn{6}{|c|}{ Blocked breathing } \\
\hline Yes & 34 & 100.0 & 0 & 0.0 & 0.0001 \\
\hline No & 0 & 0.0 & 34 & 100.0 & \\
\hline \multicolumn{6}{|l|}{ Dry mouth } \\
\hline Yes & 34 & 100.0 & 0 & 0.0 & 0.0001 \\
\hline No & 0 & 0.0 & 34 & 100.0 & \\
\hline
\end{tabular}

Table 3 shows VAS grade pre and post radiofrequency coblation for treatment of inferior turbinate hypertrophy; the difference was statistically highly significant.

Table (3): Comparison of VAS grade pre and post radiofrequency coblation for treatment of inferior turbinate hypertrophy (N. 34 sides)

\begin{tabular}{|c|c|c|c|c|}
\hline & & \multicolumn{2}{|c|}{$\begin{array}{c}\text { Radiofrequency Coblation } \\
\text { side }\end{array}$} & \multirow{2}{*}{$\mathbf{P}$} \\
\hline & & $\begin{array}{c}\text { Pre } \\
\text { intervention }\end{array}$ & $\begin{array}{c}\text { Post } \\
\text { intervention }\end{array}$ & \\
\hline \multirow{6}{*}{ VAS } & \begin{tabular}{|l} 
N. \\
\end{tabular} & 0 & 32 & \multirow{6}{*}{$<0.0001$} \\
\hline & $\begin{array}{ll}\text { Grade } \% \\
\end{array}$ & 0.0 & $94.1 \%$ & \\
\hline & Grade? N. & 12 & 2 & \\
\hline & Grade $2 \%$ & $35.3 \%$ & $5.9 \%$ & \\
\hline & \multirow{2}{*}{\begin{tabular}{|l|l} 
Grade 3 & $\mathrm{~N}$. \\
$\%$
\end{tabular}} & 22 & 0 & \\
\hline & & $64.7 \%$ & 0.0 & \\
\hline
\end{tabular}

VAS grade pre and post surface bipolar cauterization of inferior turbinate hypertrophy side is shown in figure 1 . The difference was statistically highly significant.

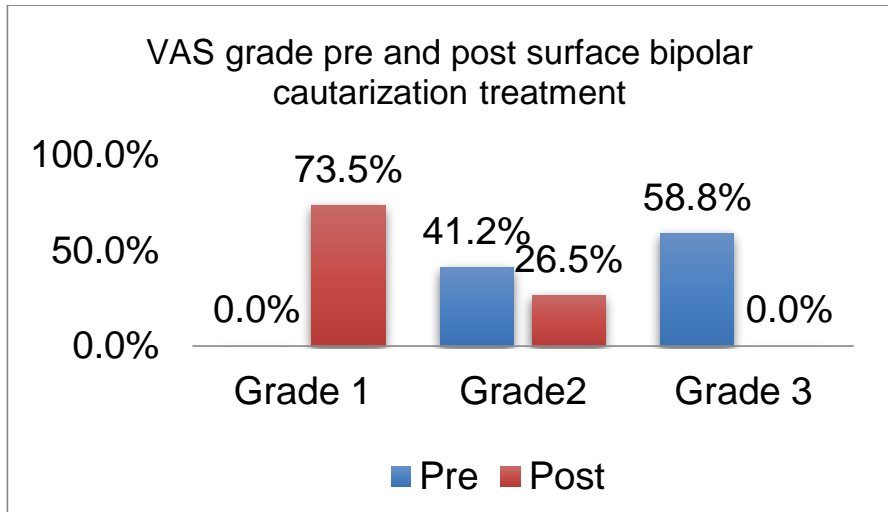

Figure (1): Percent of VAS grade pre and post surface bipolar cauterization for treatment inferior turbinate hypertrophy

Table 4 shows that there was a significant difference between the 2 types of treatment as regard incidence of complication.

Table (4): Comparison complication of radiofrequency coblation versus surface bipolar cauterization for the treatment of inferior turbinate hypertrophy (each 34 sides)

\begin{tabular}{|c|c|c|c|c|c|}
\hline \multicolumn{2}{|c|}{} & & $\begin{array}{c}\text { Radio- } \\
\text { frequency } \\
\text { Coblation } \\
\text { sides }\end{array}$ & $\begin{array}{c}\text { Surface } \\
\text { Bipolar } \\
\text { Cauterization } \\
\text { sides }\end{array}$ & \multirow{2}{*}{ P } \\
\hline \hline \multirow{2}{*}{$\begin{array}{c}\text { Complication } \\
\text { (pain) }\end{array}$} & Yes & N. & 10 & 18 & \multirow{2}{*}{0.049} \\
\cline { 3 - 5 } & No & N. & $29.4 \%$ & $52.9 \%$ & \\
\cline { 3 - 5 } & \% & 24 & 16 & \\
\hline
\end{tabular}


Table (5) shows that there was a significant difference between the 2 types of treatment as regard pain duration.

Table (5): Comparison of duration of postoperative pain among radiofrequency coblation versus surface bipolar cauterization for the treatment of inferior turbinate hypertrophy

\begin{tabular}{|c|c|c|c|}
\hline & $\begin{array}{c}\text { Radio- } \\
\text { frequency } \\
\text { Coblation } \\
\text { sides } \\
\mathbf{N = 1 0}\end{array}$ & $\begin{array}{c}\text { Surface } \\
\text { Bipolar } \\
\text { Cauterization } \\
\text { sides } \\
\mathbf{N}=18\end{array}$ & $\mathbf{P}$ \\
\hline \hline $\begin{array}{c}\text { Duration } \\
\text { of pain } \\
\text { (week) } \\
\begin{array}{c}\text { Median } \\
\text { (range) }\end{array}\end{array}$ & $1(1-1$ week $)$ & $1(1-2$ weeks $)$ & 0.025 \\
\hline
\end{tabular}

Table 6 shows that there was non-significant difference between the 2 types of treatment as regard VAS grade at pre intervention.

Table (6): Comparison VAS grade pre the treatment of inferior turbinate hypertrophy (each 34 sides)

\begin{tabular}{|c|c|c|c|c|c|}
\hline & \multicolumn{4}{|c|}{ Pre intervention } & \multirow[b]{2}{*}{$\mathbf{P}$} \\
\hline & & & \begin{tabular}{|c|} 
Radio- \\
frequency \\
Coblation \\
side \\
\end{tabular} & \begin{tabular}{|c|} 
Surface \\
Bipolar \\
$\begin{array}{c}\text { Cauterization } \\
\text { side }\end{array}$ \\
\end{tabular} & \\
\hline \multirow{4}{*}{ VAS } & Grade & N. & 12 & 14 & \multirow{4}{*}{0.62} \\
\hline & 2 & $\%$ & $35.3 \%$ & $41.2 \%$ & \\
\hline & \multirow{2}{*}{$\begin{array}{c}\text { Grade } \\
\mathbf{3}\end{array}$} & N. & 22 & 20 & \\
\hline & & $\%$ & $64.7 \%$ & $58.8 \%$ & \\
\hline
\end{tabular}

Table 7 shows that there was significant difference between the 2 types of treatment as regard VAS grade postoperatively.

Table (7): Comparison post intervention VAS grade of radiofrequency coblation versus surface bipolar cauterization for the treatment of inferior turbinate hypertrophy (each side N.34)

\begin{tabular}{|c|c|c|c|c|c|}
\hline & \multicolumn{4}{|c|}{ Post intervention } & \multirow[b]{2}{*}{$\begin{array}{c}p- \\
\text { value }\end{array}$} \\
\hline & & & $\begin{array}{c}\text { Radio- } \\
\text { frequency } \\
\text { Coblation } \\
\text { side } \\
\end{array}$ & $\begin{array}{c}\text { Surface } \\
\text { Bipolar } \\
\text { Cauterizat } \\
\text { ion side } \\
\end{array}$ & \\
\hline \multirow{4}{*}{ VAS } & Grade & N. & 32 & 25 & \multirow{4}{*}{0.021} \\
\hline & 1 & $\%$ & $94.1 \%$ & $73.5 \%$ & \\
\hline & \multirow{2}{*}{$\begin{array}{c}\text { Grade } \\
2\end{array}$} & N. & 2 & 9 & \\
\hline & & $\%$ & $5.9 \%$ & $26.5 \%$ & \\
\hline
\end{tabular}

\section{DISCUSSION}

The studied patients were 24 females $(70.6 \%)$ and 10 males (29.4\%), the mean age of all patients was $28.4 \pm 8.3$ years and it ranged from (17-72) years, where 16 patients of them were non-smokers $(47.1 \%), 10$ patients were passive smokers $(29.4 \%)$ and 8 patients were smokers $(23.5 \%)$. However, in the study of Unsal et $\boldsymbol{a l .}{ }^{(7)}$, twenty-seven patients were included in their study; with a mean age of $32.16 \pm 10.48$ years old (range 20-59). There were 6 females $(22.2 \%)$ and 21 males $(77.8 \%)$.

The present study showed that among the studied patients, there were 18 patients (52.9\%) and 16 patients $(47.1 \%)$ had grade III and grade IV of inferior turbinate hypertrophy respectively. All patients (100.0\%) had resistant allergic rhinitis to treatment but responded to topical decongested. However, in the study of Rao et al. (8), the main symptom prior to surgery was $100 \%$ nasal obstruction in patients.

The current study showed that on comparing symptoms pre- and post-surgical treatment of inferior turbinate hypertrophy among studied patients; 26 cases (76.5\%) had headache, which was relieved to be 14 cases $(41.2 \%)$ post intervention, the difference was statistically highly significant. 14 Cases $(41.2 \%)$ had nasal itching, which was relieved to be e 8 cases $(23.5 \%)$ post intervention, the difference was statistically significant. Moreover; all cases (100\%) had running nose, blocked breathing, and dry mouth. These symptoms were relived completely among all cases post intervention, the difference was statistically highly significant. While there was statistically no significant difference as regard sneezing symptom post intervention.

Our results were supported by study of Sabaaa $\boldsymbol{e t}$ al. ${ }^{(9)}$ as they reported that regarding TNSS (total nasal symptom score), the baseline mean (SD) was 5 (2), 5 (2), and 5 (1) for groups A, B, and C, respectively, with no statistically significant difference among the 3 groups (P $=0.8)$. Three months after surgery, the mean (SD) declined to 3 (2), 3 (2), and 3 (1) for groups A, B, and C, respectively. Yet, no statistical significance was detected among the groups $(\mathrm{P}=0.8)$. Pairwise comparison of baseline with 3-month follow-up data of each group showed a statistical significance, with a $\mathrm{P}$ value less than 0.001 . This randomized controlled trial was carried out on 45 patients with hypertrophied inferior turbinates, who were randomly divided into three equal groups: group A underwent partial inferior turbinectomy, group B was subjected to inferior turbinate bipolar surface cautery, and group $\mathrm{C}$ underwent inferior turbinoplasty.

Also, Türk $\boldsymbol{e t} \boldsymbol{a l} .{ }^{(\mathbf{1 0})}$ demonstrated that a statistically significant improvement in rhinorrhea, itching, and sneezing symptoms was observed in group 1 postoperatively. On the other hand, there was no statistically significant difference in the VAS scores of rhinorrheas and itching postoperatively in group 2 (the patients with allergic rhinitis $(n=23)$ were classed as group 1 , and the patients with non-allergic rhinitis $(n=36)$ were classed as group 2). Only a significant symptomatic improvement in sneezing was observed. It remains unclear how radiofrequency ablation (RFA) turbinate surgery reduces rhinorrhea, itching, and sneezing symptoms in patients with allergic rhinitis and sneezing in patients with non-allergic rhinitis. In some 
studies, the relief of sneezing after RFA was attributed to the destruction of the post-nasal nerve branches ${ }^{(\mathbf{1 1 )}}$.

However, posterior nasal nerve responsible for the innervation of nasal mucosa is distributed on the whole nasal mucosa, so it is strange that just turbinate reduction can have so striking results. Furthermore, it has been suggested that dysregulation of sympathetic, parasympathetic, and nociceptive nerves innervating the nasal mucosa and regulating the nasal mucosal vascularity and glandular secretion. The application of RF energy to inferior turbinate submucosa induces submucosal small vessel obliteration and mucosal gland destruction, circumferential scar formation that are considered to play major role for these beneficial effects of RFA ${ }^{(12)}$.

Radiofrequency ablation (RFA) is a technique that was developed in 1998 at Stanford University in the US and is being used and recognized as a minimally invasive and effective mode of treatment when compared to surgery. RFA uses radiofrequency waves to deliver energy to tissue $2-4 \mathrm{~mm}$ depth from the electrode head, subsequently denaturing the tissue proteins in the deep mucosa whilst preserving the surface tissue. The ablated tissue then scars and shrinks with time resulting in reduced nasal blockage and improving patient symptoms ${ }^{(13)}$.

In the study, as regard VAS grade pre and post radiofrequency coblation for treatment inferior turbinate hypertrophy side; 12 cases (35.3\%) suffered from VAS grade 2 and 22 cases $(64.7 \%)$ grade 3 . This declined post intervention to be 32 cases $(94.1 \%)$ had VAS grade1, only 2 patients $(5.9 \%)$ had VAS grade 2 , the difference statistically was highly significant.

Our results were supported by study of Unsal $\boldsymbol{e t}$ al. (7) as they revealed that the post-ablation measurements revealed that the inferior turbinate ablation caused an increase in the mean cross-sectional area and volume of the nose, as well as in the forced expiratory volume in 1 second, forced vital capacity, and peak expiratory flow of the patients. These differences between the pre- and post-ablation results were statistically significant. The post-ablation visual analogue scale (VAS) scores were lower when compared with the pre-ablation scores, and this difference was also statistically significant.

Also, Türk et al. ${ }^{(\mathbf{1 0 )})}$ reported that in both groups, the postoperative endoscopic examination revealed that there was a statistically significant decrease in nasal obstruction. A statistically significant decrease in the obstruction rate was detected at the postoperative sixth month in comparison to findings at the postoperative third month in group $1 \quad(\mathrm{p}<0.001)$. There was no statistically significant difference in the degree of nasal obstruction between the two groups preoperatively or at the postoperative third month $(\mathrm{p}=0.218$ and $\mathrm{p}=0.922$, respectively). However, the percentage of obstruction of the nasal cavity due to the inferior turbinate at the postoperative sixth month was significantly higher in group 1 than that in group $2(\mathrm{p}=0.004)$.

Acoustic rhinometry (AR) provides an objective measurement of the cross-sectional areas of the corresponding sections in the nose, and $\mathrm{AR}$ improvement after an RFA of the inferior turbinate has been reported in several studies ${ }^{(14,15)}$.

A variety of surgical methods have been used in the past for reduction of hypertrophied inferior turbinate. These include submucosal cautery, laser turbinate reduction, micro debridement, surface cautery, and excision of the inferior turbinate. These techniques are limited by considerable morbidity, including blood loss, a prolonged procedure, and postoperative pain and crusting $^{(16)}$.

The present study showed that VAS grade pre and post surface bipolar cauterization of inferior turbinate hypertrophy side; 14 cases $(41.2 \%)$ suffered from VAS grade 2 and 20 cases $(58.8 \% \%)$ grade 3 . This declined post intervention to be 25 cases $(73.5 \%)$ had VAS grade 1 , and 9 patients $(26.5 \%)$ had VAS grade 2 , the difference was statistically highly significant $\mathrm{p}=0.0001$.

This results were supported by study of Uluyol $\boldsymbol{e} t$ al. (17) as they reported that in the BEC (bipolar electrocautery) group, the mean MCC (mucociliary clearance) was $570.6 \pm 61$ seconds (range: 4351 to 735 seconds) before treatment and $584.9 \pm 61$ seconds (range: 460 to 690 seconds) 2 months after treatment, and the difference between two tests was not statistically significant ( $\mathrm{p}, 0.75)$. Mean VAS score for nasal patency was $7.1 \pm 1.13$ before treatment and $3.4 \pm 1.02$ months after treatment, and the difference between the two results was statistically significant (p, 0.001).

Inferior turbinate hypertrophy (ITH), although often overshadowed by nasal septal deviation, is a common cause of chronic nasal obstruction. ITH is commonly associated with chronic allergic or vasomotor rhinitis, which affects an estimated 30 million Americans. These conditions are traditionally treated conservatively with topical corticosteroids, antihistamines, decongestants, and immunotherapy ${ }^{(\mathbf{1 8})}$.

The current study showed that there was a significant difference between the 2 sides as regard incidence of complication as incidence of complication was $29.4 \%$ in radiofrequency coblation treated side and was $52.9 \%$ in surface bipolar cauterization treated side. There was a significant difference between the 2 sides as regard pain duration as: duration of complication: was one week in radiofrequency coblation treated side and it ranged from one week to two weeks of surface bipolar cauterization treated side. There was nonsignificant difference between the 2 sides as regard VAS grade at pre intervention.

These results were in agreement with study of Shah et al. ${ }^{(2)}$ as they reported that radiofrequency coblation was significantly less painful than bipolar cautery during the procedure $(\mathrm{P}=0.03)$ and during the early postoperative period $(\mathrm{P}<0.02)$ and produced less crusting at 3 weeks $(\mathrm{P}=0.009)$. Both interventions were similar in subjective and objective improvements in nasal obstruction as measured by acoustic rhinometry and subjective VAS outcomes. When comparing each patient's subjective assessment (VAS scale) of their level of nasal obstruction prior to turbinate reduction, both the coblation and cautery 
group were similar ( 46 vs $50 ; \mathrm{P}=0.30$ ). At the 6-week follow-up, while only 24 of the 41 patients completed the VAS questionnaire for level of nasal obstruction, the coblation group demonstrated a $63 \%$ improvement, and the bipolar cautery group demonstrated a 54\% improvement (17 vs $23 ; \mathrm{P}=0$.14)

Also, Salem et al. ${ }^{(19)}$, demonstrated that coblation was less painful during the procedure and in the postoperative period than bipolar cautery. Nasal obstruction improved significantly by both techniques, but more improvement was observed in the side treated by coblation. Both of the two techniques reduced the hypertrophied inferior turbinate significantly.

\section{CONCLUSION}

Both techniques have proven to be equally effective. In both groups, radiofrequency is considered to be more accurate. Bipolar electrocautery and radiofrequency volumetric tissue reduction are equally effective in improving both the subjective and objective nasal obstruction.

\section{RECOMMENDATION}

More researches are needed with longer follow up for assessment of more outcomes and for developing simplified patient satisfaction score for evaluation of each technique.

\section{REFERENCES}

1. Badawy B, Aarf Z, AbdElrahman $N$ et al. (2018): Endoscopic evaluation of surgical inferior partial turbinectomy versus coblation assisted turbinectomy. SVU- International Journal of Medical Sciences, 2(2): 116-122.

2. Shah A, Brewster D, Mitzen $K$ et al. (2015): Radiofrequency coblation versus intramural bipolar cautery for the treatment of inferior turbinate hypertrophy. Annals of Otology, Rhinology \& Laryngology, 124(9): 691-697.

3. Bozan A, Eriş H, Dizdar D et al. (2019): Effects of turbinoplasty versus outfracture and bipolar cautery on the compensatory inferior turbinate hypertrophy in septoplasty patients. Brazilian Journal of Otorhinolaryngology, 85(5): 565-570.

4. Kaplama M, Kaygusuz I, Akpolat $N$ et al. (2013): Comparison of the histologic changes in conchae induced by radiofrequency thermal ablation and submucosal diathermy. European Archives of Oto-RhinoLaryngology, 270(11): 2901-2907.

5. Wolfswinkel E, Koshy J, Kaufman Y et al. (2010): A modified technique for inferior turbinate reduction: the integration of coblation technology. Plastic and Reconstructive Surgery, 126(2): 489-491.
6. Saeed I, Akhlaq M, Rehman A (2015): Comparison of the surface cautery and submucuos diathermy in relation to relief of nasal obstruction caused by hypertrophied inferior turbinates. Pakistan Journal of Medical \& Health Sciences, 9(2): 629-632.

7. Unsal O, Ozkahraman M, Ozkarafakili M et al. (2019): Does the reduction of inferior turbinate affect lower airway functions? Brazilian Journal of Otorhinolaryngology, 85: 43-49.

8. Rao S, Basavaraj P, Yempalle S et al. (2017): A prospective study of different methods of inferior turbinate reduction. Journal of Clinical and Diagnostic Research, 11(5): 1-6.

9. Sabaaa M, Haithamb M, El-Essawya M et al. (2020): Endoscopic score: a new method for evaluating different inferior turbinate reduction techniques. Pan Arab Journal of Rhinology, 10(1): 27-31.

10. Türk B, Korkut A, Kaya $K$ et al. (2018): Results of radiofrequency ablation of inferior turbinate hypertrophy in patients with allergic and non-allergic rhinitis. The Medical Bulletin of Sisli Etfal Hospital, 52(4): 296-302.

11. Lin H, Lin P, Friedman M et al. (2010): Long-term results of radiofrequency turbinoplasty for allergic rhinitis refractory to medical therapy. Arch Otolaryngol Head Neck Surg., 136:892-5.

12. Bernstein J (2013): Nonallergic rhinitis: therapeutic options. Curr Opin Allergy Clin Immunol., 13:410-6.

13. Kumar K, Kumar S, Garg S (2014): A Comparative study of radiofrequency assisted versus microdebrider assisted turbinoplasty in cases of inferior turbinate hypertrophy. Indian J Otolaryngol Head Neck Surg., 66:35-9.

14. Demir U, Durgut O, Saraydaroglu G et al. (2012): Efficacy of radiofrequency turbinate reduction: evaluation by computed tomography and acoustic rhinometry. J Otolaryngol Head Neck Surg., 41:274-81.

15. Passali D, Loglisci M, Politi L et al. (2016): Managing turbinate hypertrophy: coblation vs. radiofrequency treatment. Eur Arch Otorhinolaryngol., 273:1449-53.

16. Jiang $Z$, Pereira $K$, Friedman $N$ et al. (2012): Inferior turbinate surgery in children: a survey of practice patterns. The Laryngoscope, 122(7): 1620-1623.

17. Uluyol S, Karakaya N, Gur M et al. (2016): Radiofrequency thermal ablation versus bipolar electrocautery for the treatment of inferior turbinate hypertrophy: comparison of efficacy and postoperative morbidity. International Archives of Otorhinolaryngology, 20(01): 2-5.

18. Komshian S, Cohen M, Brook C et al. (2019): Inferior turbinate hypertrophy: a review of the evolution of management in children. American Journal of Rhinology \& Allergy, 33(2): 212-219.

19. Salem M, Hassanin M, Saleh Kayed E (2019): Submucosal diathermy versus coblation for reduction of hypertrophied inferior turbinate. Egyptian Journal of Neck Surgery and Otorhinolaryngology, 5(1): 19-29. 